\title{
Risk Level Assessment in Construction Projects Using the Schedule Performance Index
}

\author{
Roberto Barbosa dos Santos ${ }^{1}$ and Antônio Edésio Jungles ${ }^{2}$ \\ ${ }^{1}$ Federal University of Alagoas, Maceió, AL, Brazil \\ ${ }^{2}$ Federal University of Santa Catarina, Florianópolis, SC, Brazil \\ Correspondence should be addressed to Roberto Barbosa dos Santos; rbs@ctec.ufal.br
}

Received 7 June 2016; Accepted 5 October 2016

Academic Editor: Edwin H. W. Chan

Copyright ( 2016 R. B. D. Santos and A. E. Jungles. This is an open access article distributed under the Creative Commons Attribution License, which permits unrestricted use, distribution, and reproduction in any medium, provided the original work is properly cited.

\begin{abstract}
Construction projects are risky in both physical implementation and management. The characteristics of the risk reinforce the necessity of efficient management to increase the chances of success without commitment to its goals. This study explores the correlation of delay and the schedule performance index (SPI) to evaluate the risk of a construction project completed with time overruns. The hypothesis that the SPI of projects with a delay is distinct from those projects without a delay is assumed. A database with 19 elements was used to test this hypothesis and to calculate limit values to the SPI. Therefore, the risk of delay will be small when the observed SPI is greater than the superior limit and large when the SPI is below the inferior limit. The simplicity involved in the calculation of these values showed an advantage in comparison with other methods of risk evaluation. Another strong point observed is that any company can determine the value of risk by considering its own history and support decisions like doing corrective actions.
\end{abstract}

\section{Introduction}

Construction projects display risks in the physical implementation and in the management process because construction projects comprise a significant portion of all work accidents in Brazil (Table 1) and display variations from the planned cost and time at the end of the projects.

Two studies developed by the National Audit Office of the United Kingdom presented that there were delays in

(i) $70 \%$ of public construction projects, and $73 \%$ of those projects were delivered with cost overruns [1],

(ii) $24 \%$ of public construction projects contracted under the Private Finance Initiative, and 22\% of those projects were delivered with cost overruns [2].

These numbers validate the assumption that delays are culturally accepted in the construction industry [3], so much that in Malaysian Construction industry a survey shows that their probability was evaluated only as high or very high, never as very low, low, or moderate [4]. Various causes explain the variations observed at the end of construction projects, and these causes can be grouped into the following: external factors, project complexity, incompetent project management, and unrealistic estimates [5]. The results of a recent study conducted in Ghana are aligned with these statements, because price fluctuation, late material delivery, changes in the scope of work, fluctuations on marketing demand, and changes in design were pointed as the most important factors on cost variations on project at its completion [6].

Many previous works show the behavior and magnitude of cost and schedule overruns [7], but it is not possible yet to recognize a consistent behavior pattern, because sometimes the conclusions agree and sometimes disagree. Then still more studies are necessary about cost and schedule overruns to understand its causes and behavior to be able to forecast its magnitude. Independent from the context of behavior and magnitudes, the use of contingencies is the basic strategy to combat risky events [5] that threaten the established goals.

Although the risks of occupational accidents and project overruns are important and must be considered, this study focuses on analyzing the risk of delays in residential constructions. Delays deserve attention because they cause and 
TABLE 1: Occupational accidents share in Brazilian construction industry.

\begin{tabular}{lccc}
\hline & \multicolumn{3}{c}{ Year } \\
& 2010 & 2011 & 2012 \\
\hline Occupational accidents & $7.88 \%$ & $8.38 \%$ & $8.92 \%$ \\
\hline
\end{tabular}

Source: Ministério da Previdência Social (http://www.previdencia.gov.br/ estatisticas/aeat-2012/estatisticas-de-acidentes-do-trabalho-2012/subsecaoa-acidentes-do-trabalho-registrados/).

result from other risks. From the correlation between the level of delay in a specific moment of implementation and the delay at the end of the project, this work proposes a simple procedure to evaluate the level of risk in residential construction projects.

Before presenting the procedure, the risk management will be contextualized inside the project management framework. Then, the delays will be analyzed as a condition with a probability of occurrence associated with a group of variables that depend on the vulnerability level of the environment.

\section{Project and Risk Management}

The focus of project management is to deliver a specific product in accordance with time, cost, quality, and scope goals. Among all areas recognized as essential to the management of a construction project, the most critical are the management of time, cost, and risk [8]. Thus, those specific types of management must plan, track, and control their subjects to increase the chances of the success of the project.

For time and cost management, this work investigates the control obtained by measuring a specific performance index. Acknowledging that implementation is a process which is distributed in time, every project will have a set of variables that characterize its state at a given moment in time. These variables include the following:

(i) The planned value $\left(P V_{i}\right)$ represents the budgeted cost for the work scheduled at any instant of time $i$ (e.g., week, month, or year) and changes between 0 and $100 \%$.

(ii) The earned value $\left(\mathrm{EV}_{i}\right)$ is the budgeted cost of the work executed until time $i$ and is limited to values of $0 \%$ to $100 \%$.

(iii) The actual cost $\left(\mathrm{AC}_{i}\right)$ is the cost incurred to perform the work executed until time $i$.

The SPI is the ratio between the earned and planned values and is calculated by (1). In any instant of time, $i$, inferior or superior values of $\mathrm{SPI}_{i}$ indicate that the project is delayed or advanced, respectively, relative to the planned values. However, when a project is delayed or advanced during the implementation, this momentary delay does not imply that this identical project will finish with a delay. This value only implies that the project is exposed to the risk of delay; this risk can be evaluated as high, normal, or low according to the management of risk.

$$
\mathrm{SPI}_{i}=\frac{\mathrm{EV}_{i}}{\mathrm{PV}_{i}}
$$

The focus of risk management is to minimize the occurrence of and damage from negative events and maximize the occurrence of and results from positive events. Therefore, the risk management must be planned to identify and analyze risk qualitatively and quantitatively and to monitor and control the risks [8].

Risk management can be divided into analyzing and managing risk. A structure of the processes and activities involved in risk management is available in a previous study [9].

The effects of variability and uncertainty in the implementation of construction projects result from the characteristics of the construction industry and its production system. Scientific computation and statistics have advanced the techniques and available tools to plan and control projects in every area of management.

Computational simulations and statistical modeling of observational data have been used to solve management problems associated with time, cost, and risk. The use of stochastic $S$ curves in controlling construction projects [10, 11] is an example of using simulation and data analysis.

Regression models used for estimation and prediction are examples of statistical modeling, in which the construction costs have been the focus of the analysis [12, 13]. Once the implementation of a construction project is formally understood as a dynamic system, sophisticated mathematical formulas can be used in the management and prediction of risk $[14,15]$.

Among the difficulties faced in managing risks associated with construction projects are the necessity of monitoring many variables and the fragility of the analysis methods [16] and in many times it is necessary to deal with lack of knowledge and interest into manage risks accordingly [17]. When data are available, the data can be inaccurate and/or display variable levels of randomness, increasing the uncertainty of the analysis and the importance of the opinions of specialists.

The data is initially useful in identifying risks, the causes of risks, and the effects of risks. The level of the risk bound to the project must then be evaluated. An analysis of the sensibility and a Monte Carlo simulation are traditional approaches for this evaluation [5]. Additionally, fuzzy logic is a modern approach for the evaluation of the risk, mainly in quantitative evaluations $[16,18]$. Historical data series and decision trees have also been used in the analysis [19].

Moreover, these methods consider that all possible risks are known; therefore, in using these methods, an important risk could be neglected, compromising the obtained results. After identifying and analyzing the risks, a response must be identified to address a risk (e.g., $\mathrm{SPI}_{i} \neq 1$ ). The response planning must provide one of four basic types of answers [19]: eliminate, transfer, compensate, and absolve. A nontrivial situation occurs if $\mathrm{SPI}_{i}>1$ and the project cash flow is 
constrained by sales. In this case, the risk is to commit the financial health of firm or just deal with a financial loss by early investment withdrawal. If the damage is small, a response may be to absolve the risk and take no action beyond warning project managers.

Eventually, the action taken to address the risk eliminates the effects. Therefore, a contingency plan must be designed to contain the negative effects of the observed risks.

The contingencies can be a strategic buffer included in the schedule to absolve the delays without compromising the delivery date as recommended by the Theory of Constraints [20] or financial reserves to absolve variations of cost [5].

\section{The Risk of Delay}

For the Project Management Institute, a risk is an event or uncertain condition that, after occurring, will affect the goals of the construction project [21]. A risk may have more than one cause and may result in more than one effect. Even when two projects are exposed to the identical level of risk, they may not be equally vulnerable because the projects can have distinct capacities of reacting or absolving risks.

During the implementation period of construction projects, the production system remains susceptible to uncertainty and variability, which directly affects the availability and productivity of inputs and resources. This vulnerability is maintained because all construction materials cannot be guaranteed to be available at a given moment with a specific quantity and quality and in the correct location to be manipulated by workers and equipment during the conversion into finished products or in processing.

Therefore, delays begin to be observed at the level of production activity, either because the materials lacked the expected quality or because congestion occurred between the work fluxes in the construction site. The causes of delays can be grouped into planning, worker, material, and general failures [22]. Controlling and measuring the effect of delays in a construction project is a complex task because of the quantity of activities and their connections.

The combination of those individual effects is perceived directly in $\mathrm{SPI}_{i}$, which assumes that values below 1 indicate an already present delay. Consequences of being late include increasing the cost of production, maintaining the production of resources mobilized for longer than planned, and remaining exposed to risk factors such as inflation and currency exchange for longer periods.

In addition, the Brazilian construction industry still depends heavily on human labor. Therefore, the productivity of processes is influenced by factors such as weather and mood. As a result of this vulnerability, construction projects are subject to two distinct risks: (a) exceeding the allotted time and (b) exceeding the initial budget.

During the implementation phase, a risk event that can be monitored is the low probability of completion by the planned date [15]. Another event that can be monitored is the occurrence of $\mathrm{SPI}_{i}<1$, indicating that in month $i$ a delay was noted. However, $\mathrm{SPI}_{i}$ is easier to calculate than the probability of not completing the project by the established date.
When selecting $\mathrm{SPI}_{i}$ and adopting a statistical model to manage the risk of a construction project delay, the relationship between $\mathrm{SPI}_{i}$ and the final observed delay can be established. This type of research focuses on establishing a causal relationship or exploring the correlation without causality [23]. Being late at a given time $\left(\mathrm{SPI}_{i}<1\right)$ does not imply a late finish, or being early $\left(\mathrm{SPI}_{i}>1\right)$ does not imply finishing on time. Thus, a cause and effect relationship is inappropriate between these variables.

However, being late at a given moment causes the project to be more likely to end late than end on time or early, and SPI is an indicator of this trend; therefore, a correlation should be noted between $\mathrm{SPI}_{i}$ and delay. To find this correlation, similar elements should be compared and grouped, and distinct elements should be segregated to proceed with the desired analysis.

When all elements of a sample are assumed to be similar, the relationship between $\mathrm{SPI}_{i}$ and delay cannot be explored. The limitation to this analysis may reside in the hypothesis that delayed projects are similar to projects that are delivered on time or early.

This hypothesis implies that when separating a sample of construction projects into delayed and not delayed groups, no significant differences should be noted between the groups in the resulting $\mathrm{SPI}_{i}$. If this hypothesis is rejected, then the delay of risk can be managed through $\mathrm{SPI}_{i}$, and $\mathrm{SPI}_{i}$ will be analyzed qualitatively as high, normal, and low in reference to the limiting values previously established.

The next section displays observational data for 19 construction projects already delivered, of which 15 ended late. The data are used to test the hypothesis regarding the similarity between groups and to estimate the limiting values of $\mathrm{SPI}_{i}$ at months 3, 6, 9, and 12 during the implementation. Those time intervals were selected because the early identification and mitigation of the risk increase the chance of the project being successful.

\section{Construction Projects Database}

Two construction companies provided monitoring data for their projects. All projects were residential with multiple pavements and were delivered in three cities in different periods. Table 2 shows the observed delays at the end of construction, their final and planned duration, and the SPI values in the months of the reference to all projects. The highlighted values were obtained after replanning the projects.

Table 3 shows the SPI statistics by group of projects for each month. The total sample displays high coefficients of variation of approximately $40 \%$. Furthermore, the probability of a construction project manifesting a delay (a priori, $50.00 \%$ ) in this sample is $78.95 \%$. This data does not refute the value of $70 \%$ obtained in the UK [1].

The perception that the chance of success is lower will increase the probability of delay and will change the priority of the delay within risk management. Hence, alarm systems against delays $[15,24]$ can be better initialized to enable managers to act earlier and more proactively. 
TABLE 2: Durations and delays.

\begin{tabular}{|c|c|c|c|c|c|c|c|}
\hline ID & Planned duration & Final duration & Delay & $\mathrm{SPI}_{3}$ & $\mathrm{SPI}_{6}$ & $\mathrm{SPI}_{9}$ & $\mathrm{SPI}_{12}$ \\
\hline Project 01 & 25 & 43 & 18 & 0.7938 & 0.4102 & 0.3492 & 0.3539 \\
\hline Project 02 & 18 & 36 & 18 & 1.0516 & 0.8411 & 0.5685 & 0.5578 \\
\hline Project 03 & 25 & 43 & 18 & 0.0000 & 0.2366 & 0.1935 & 0.1927 \\
\hline Project 04 & 27 & 57 & 30 & 1.3098 & 0.7279 & 0.5338 & 0.4197 \\
\hline Project 05 & 22 & 55 & 33 & 1.0273 & 0.7599 & 0.6091 & 0.4803 \\
\hline Project 06 & 24 & 34 & 10 & 0.6628 & 1.3595 & 1.2069 & 0.9597 \\
\hline Project 07 & 28 & 46 & 18 & 0.6528 & 0.7444 & 0.5235 & 0.4082 \\
\hline Project 08 & 21 & 35 & 14 & 0.9039 & 0.7693 & 0.6799 & 0.7227 \\
\hline Project 09 & 26 & 39 & 13 & 0.0000 & 0.1603 & 0.3529 & 0.3229 \\
\hline Project 10 & 25 & 32 & 7 & 0.5131 & 0.6980 & 0.7402 & 0.6722 \\
\hline Project 11 & 25 & 32 & 7 & 0.7129 & 0.6390 & 0.6414 & 0.5929 \\
\hline Project 12 & 19 & 25 & 6 & 0.9504 & 0.8943 & 0.8729 & 0.7664 \\
\hline Project 13 & 24 & 25 & 1 & 0.8644 & 0.8811 & 0.9898 & 0.9366 \\
\hline Project 14 & 23 & 26 & 3 & 0.8950 & 0.8339 & 0.8771 & 0.8453 \\
\hline Project 15 & 30 & 30 & 0 & 0.9966 & 1.0002 & 0.9893 & 0.9899 \\
\hline Project 16 & 28 & 28 & 0 & 1.0000 & 0.5919 & 0.8722 & 0.8210 \\
\hline Project 17 & 32 & 32 & 0 & 1.0000 & 1.5198 & 1.1820 & 1.1319 \\
\hline Project 18 & 32 & 36 & 4 & 0.9764 & 1.0010 & 1.0065 & 0.9767 \\
\hline Project 19 & 21 & 21 & 0 & 1.1034 & 1.1034 & 1.1460 & 1.2981 \\
\hline
\end{tabular}

TABLE 3: Statistics for the SPI.

\begin{tabular}{|c|c|c|c|c|c|}
\hline Group & Statistics & $\mathrm{SPI}_{3}$ & $\mathrm{SPI}_{6}$ & $\mathrm{SPI}_{9}$ & $\mathrm{SPI}_{12}$ \\
\hline \multirow{4}{*}{ All projects } & $N$ & 19 & 19 & 19 & 19 \\
\hline & Average & 0.8113 & 0.7985 & 0.7544 & 0.7078 \\
\hline & Variance & 0.3392 & 0.3326 & 0.2957 & 0.3011 \\
\hline & Coefficient of variation & $41.8131 \%$ & $41.6509 \%$ & $39.1985 \%$ & $42.5332 \%$ \\
\hline \multirow{4}{*}{ Delayed } & $N$ & 15 & 15 & 15 & 15 \\
\hline & Average & 0.7543 & 0.7304 & 0.6763 & 0.6139 \\
\hline & Variance & 0.3617 & 0.2958 & 0.2774 & 0.2505 \\
\hline & Coefficient of variation & $47.9535 \%$ & $40.4958 \%$ & $41.0208 \%$ & $40.8064 \%$ \\
\hline \multirow{4}{*}{ Without delay } & $N$ & 4 & 4 & 4 & 4 \\
\hline & Average & 1.0250 & 1.0538 & 1.0474 & 1.0602 \\
\hline & Variance & 0.0523 & 0.3812 & 0.1437 & 0.2032 \\
\hline & Coefficient of variation & $5.1015 \%$ & $36.1692 \%$ & $13.7161 \%$ & $19.1666 \%$ \\
\hline
\end{tabular}

The data are then used to test the hypothesis regarding the similarity between the $\mathrm{SPI}_{i}$ values and to calculate the limiting values for the delay trends in construction projects. The sequence of steps used in the processing of the data is the procedure for the risk assessment.

\section{Risk Assessment Procedure}

During construction projects, the risk of delay can be measured in several ways, but usually sophisticated mathematical approaches are used, like fuzzy logic [18] and data filtering [15], to establish what risks are more important than others or find the success probability. To do so, it is necessary to estimate and manipulate many parameters and equations, sometimes in a multivariate way. Those approaches demand a lot of effort and knowledge, which ends like a disadvantage of them.
The procedure proposed in this paper is simpler and just explores the correlation between the delay at the end of the construction project and $\mathrm{SPI}_{i}$ as stated below:

(1) Acquiring samples of delivered projects

(2) Grouping sample elements into "delivered with delay" and "delivered without delay"

(3) Calculation of $\mathrm{SPI}_{i}$ of each group and their statistics

(4) Testing the hypothesis of the similarity between groups

(5) Determining the upper and lower limit values of $\mathrm{SPI}_{i}$

Except for the sample selection that was already described, the components of this procedure will be discussed below. 
5.1. Grouping Sample Elements and Determining SPI Values. This step has a key role because it allows the separation of the data into two levels. First, useful data are identified and held to analysis. Useless data to this kind of analysis are discarded. The total database has 64 construction projects, but only 19 were useful because they had, simultaneously, a complete historical data series of planned values, earned values, and actual costs. Second, projects without delay are separated from projects delivered with delay.

It is important to note that every construction organization may have its own database and calculate all performance indexes at any time to compare them. In this case, all SPIs were calculated using (1) but were grouped into with or without delay.

Based on the data in Table 2 and evaluating $\mathrm{SPI}_{i}$ of delayed projects $\left(\mathrm{SPI}_{i, \mathrm{D}}\right)$ and projects without delay $\left(\mathrm{SPI}_{i, \mathrm{WD}}\right)$ (Table 3) separately, $\mathrm{SPI}_{i, \mathrm{WD}}$ is at least $35 \%$ higher than $\mathrm{SPI}_{i, \mathrm{D}}$, despite the reduced number of projects without delay. This result is indicative of SPI ${ }_{i, \mathrm{D}}$ and $\mathrm{SPI}_{i, \mathrm{WD}}$ being dissimilar. The next section will address the relevant statistical tests.

5.2. Hypothesis Testing of the Similarity between the Groups. The hypothesis to be tested is whether these projects have significantly different behaviors. This assessment initially tests the equality of the variances and then the equality of averages. This analysis was performed in MATLAB 2010a with the use of the anoval command.

If no significant differences are noted between the variances and the averages of the samples, then the SPI of those periods will not serve as a reference and will not be a suitable indicator for the late risk of a project. However, if significant differences are noted between samples, then the limiting values for this indicator can be calculated with the desired degree of confidence.

Based on these values, the managers of construction projects or planning analysts may assess whether the observed $\mathrm{SPI}_{i}$ display sufficiently large variations to warrant management interventions in the production process to avoid delays at the end of the projects.

To prevent distortions in the calculation of the limiting values, all SPI values obtained from replanning were excluded from the sample. Therefore, the value of $n$ was reduced because select data were discarded.

The results of the analysis of $\mathrm{SPI}_{i}$ in each moment of the construction separately and the corresponding ANOVA test are displayed in Table 4.

In the reference months, the SPIs of projects with delays are significantly different from the SPIs of projects delivered on time or early. Figure 1 graphically illustrates the comparison between the samples at months 3, 6, 9, and 12. For each group of construction projects, this figure depicts the maximum and minimum values, the median, and the $25 \%$ and $75 \%$ percentiles. Outliers are individually located outside the maximum and minimum limits for each set of data, as seen in months 3 and 6.

Additionally, the behaviors of the projects (with delay and without delay) increasingly diverged as time passes because the value of $F$ increases and the value of $P$ decreases. Therefore, the hypothesis that construction projects with
TABLE 4: ANOVA for $\mathrm{SPI}_{i}$.

\begin{tabular}{lcccccc}
\hline & Source & SS & Df & MS & $F$ & Prob $>F$ \\
\hline & Groups & 0.23144 & 1 & 0.23144 & 2.14 & 0.1619 \\
$\mathrm{SPI}_{3}$ & Error & 1.83985 & 17 & 0.10823 & & \\
& Total & 2.07129 & 18 & & & \\
\hline \multirow{4}{*}{$\mathrm{SPI}_{6}$} & Groups & 0.26428 & 1 & 0.26428 & 2.85 & 0.1123 \\
& Error & 1.39334 & 15 & 0.09289 & & \\
& Total & 1.65763 & 16 & & & \\
\hline \multirow{5}{*}{$\mathrm{SPI}_{9}$} & Groups & 0.31617 & 1 & 0.31617 & 7.72 & 0.0167 \\
& Error & 0.49148 & 12 & 0.04096 & & \\
& Total & 0.80766 & 13 & & & \\
\hline \multirow{5}{*}{$\mathrm{SPI}_{12}$} & Groups & 0.37138 & 1 & 0.37138 & 6.1 & 0.0355 \\
& Error & 0.54768 & 9 & 0.06085 & & \\
& Total & 0.91906 & 10 & & & \\
\hline
\end{tabular}

TABle 5: Limit value for SPI.

\begin{tabular}{lcccc}
\hline Group & \multicolumn{4}{c}{ Limiting value } \\
& $\mathrm{SPI}_{3}(n)$ & $\mathrm{SPI}_{6}(n)$ & $\mathrm{SPI}_{9}(n)$ & $\mathrm{SPI}_{12}(n)$ \\
\hline $\begin{array}{l}\text { Delayed } \\
\left(\mathrm{SPI}_{\mathrm{LL}}\right)\end{array}$ & $0.8740(15)$ & $0.8096(13)$ & $0.8032(10)$ & $0.8070(7)$ \\
$\begin{array}{l}\text { Not delayed } \\
\left(\mathrm{SPI}_{\mathrm{UL}}\right)\end{array}$ & $0.9915(4)$ & $0.8603(4)$ & $0.9553(4)$ & $0.9300(4)$ \\
\hline
\end{tabular}

a tendency to delay have a significantly different behavior from construction projects without this trend was not rejected. Therefore, the limiting values can be calculated based on the desired degree of reliability.

5.3. Determining the Upper and Lower Limiting Values for SPI. As expected and can be seen in Table 3 and Figure 1, the average values of construction projects with a delay are lower than the average value of construction projects without delays.

For a reliability of $90 \%$, Table 5 shows the maximum and minimum values of the confidence interval for each evaluation period. As the data of Table 3 always refer to a sample, the upper and lower limit values were computed assuming a distribution of the averages, in which $\mathrm{SPI}_{i, \mathrm{D}}$ and $\mathrm{SPI}_{i, \mathrm{WD}}$ were calculated by (2) and (3), respectively. $\overline{\mathrm{SPI}}_{i, \mathrm{D}}$ and $\overline{\mathrm{SPI}_{i, \mathrm{WD}}}$ are the averages from $\mathrm{SPI}_{i, \mathrm{D}}$ and $\mathrm{SPI}_{i, \mathrm{WD}}$.

Thus, the maximum value associated with projects with a delay will be the lower limit $\left(\mathrm{SPI}_{i, \mathrm{LL}}\right)$ and the minimum value associated with projects without delay will be the upper limit $\left(\mathrm{SPI}_{i, \mathrm{UL}}\right)$. Figure 2 illustrates this condition.

As stated, the ideal value for SPI is 1.00 ; therefore, values below 1.00 indicate a delay and values above 1.00 indicate progress in relation to what was planned. Therefore, construction projects with a delay will be associated with a maximum value of SPI ${ }_{i}$. By contrast, projects without delays will be associated with a minimum value of $\mathrm{SPI}_{i}$.

$$
\begin{aligned}
\mathrm{SPI}_{i, \mathrm{D}} & =\overline{\mathrm{SPI}_{i, \mathrm{D}}}+t_{\alpha}\left(\frac{s}{\sqrt{n}}\right), \\
\mathrm{SPI}_{i, \mathrm{WD}} & =\overline{\mathrm{SPI}_{i, \mathrm{WD}}}-t_{\alpha}\left(\frac{s}{\sqrt{n}}\right) .
\end{aligned}
$$




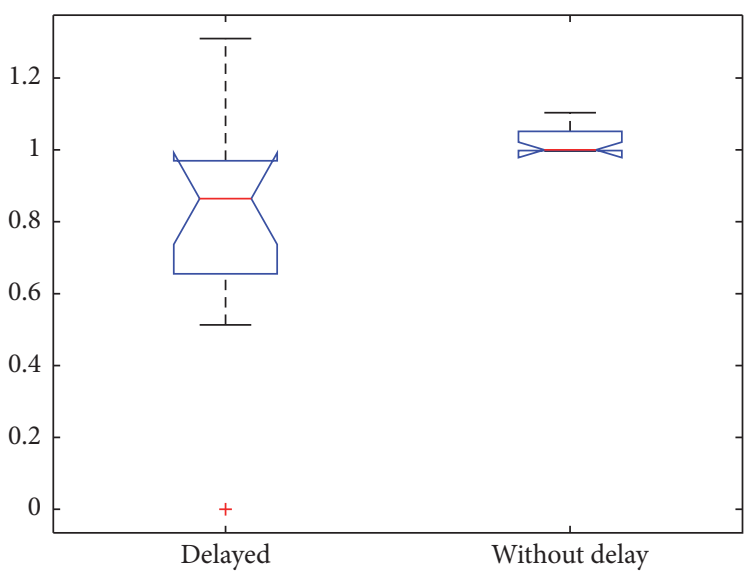

(a) $\mathrm{SPI}_{3}$

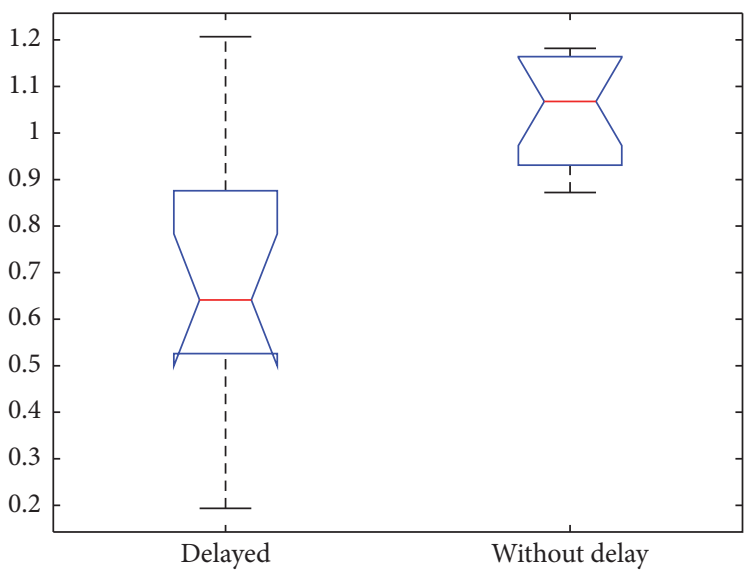

(c) $\mathrm{SPI}_{9}$

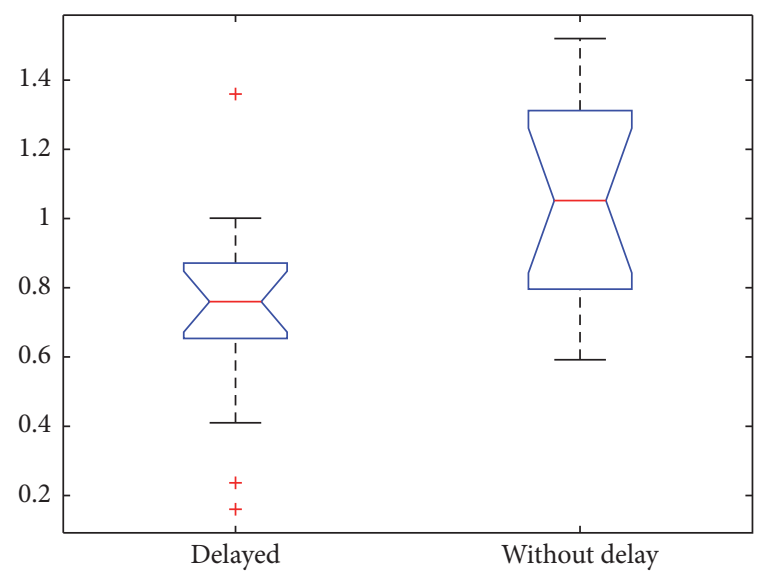

(b) $\mathrm{SPI}_{6}$

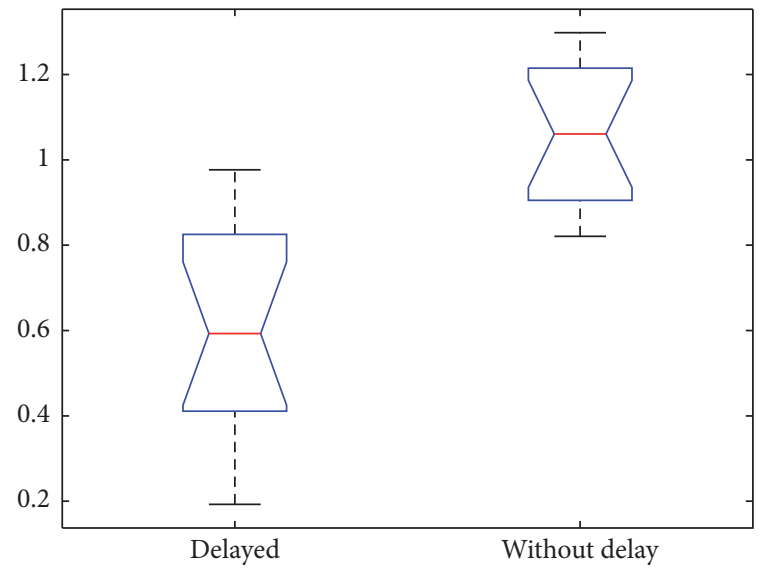

(d) $\mathrm{SPI}_{12}$

FIGURE 1: Comparing the SPIs in reference months.

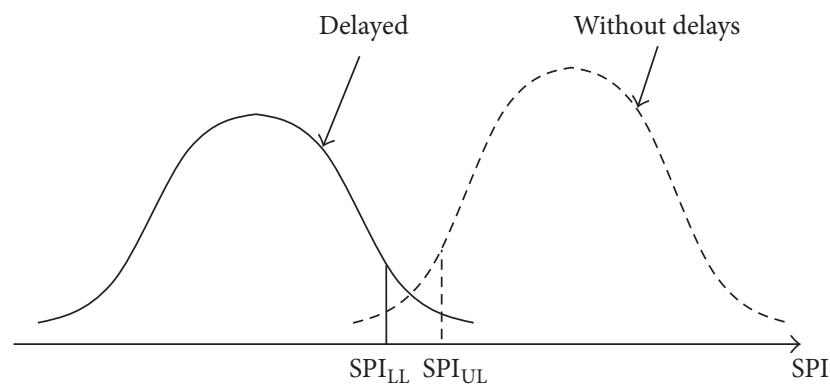

FIGURE 2: Upper and lower limiting values for SPI.

Throughout the implementation of a construction project, the observed values of the SPI $\left(\mathrm{SPI}_{i}\right)$ have to be compared to the SPI limits to assist managers in deciding for a managerial intervention in the production system. This comparison must be performed as follows:

(1) $\mathrm{SPI}_{i} \leq \mathrm{SPI}_{i, \mathrm{LL}}$ represents a project at a high risk of delay because the implementation has a delay trend. This context requires immediate management action to reverse the trend.
(2) $\mathrm{SPI}_{i, \mathrm{LL}} \leq \mathrm{SPI}_{i} \leq \mathrm{SPI}_{i, \mathrm{UL}}$ represents a project with normal risk of delay, in which the implementation can be considered normal because the trend in the construction project cannot be deduced. In this case, an intervention in the production system is performed at the discretion of the manager or in accordance with the response plan for risk.

(3) $\mathrm{SPI}_{i} \geq \mathrm{SPI}_{i, \mathrm{UL}}$ represents a project with low risk of delay because the implementation is ahead of what was planned. In this condition, managerial intervention remains at the discretion of the manager and the risk response plan because the early completion can develop other risks by pressing the project cash flow and reducing the financial profit arising from the use of investments in advance.

It is important to note that a condition with a lot of uncertainty occurs when $\mathrm{SPI}_{i}$ is equal to one of limit values, a border condition; in this way whether a specific month has its SPI on limit, a priori, a corrective action is not necessary but is desirable and suggested to work to reach the middle of next interval $\left(\mathrm{SPI}_{i+1, \mathrm{LL}} ; \mathrm{SPI}_{i+1, \mathrm{UL}}\right)$. 


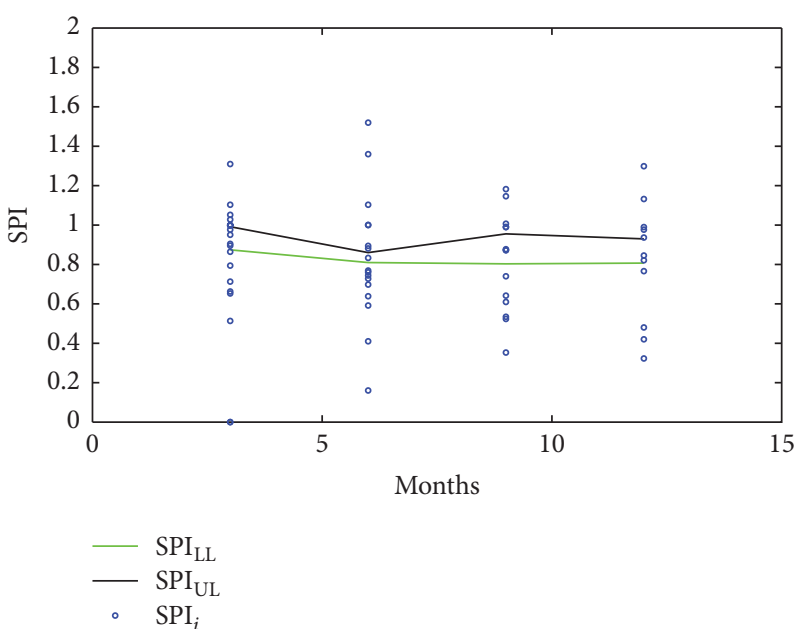

FIGURE 3: Comparison between $\mathrm{SPI}_{i}, \mathrm{SPI}_{\mathrm{LL}}$, and $\mathrm{SPI}_{\mathrm{UL}}$ without replanned values.

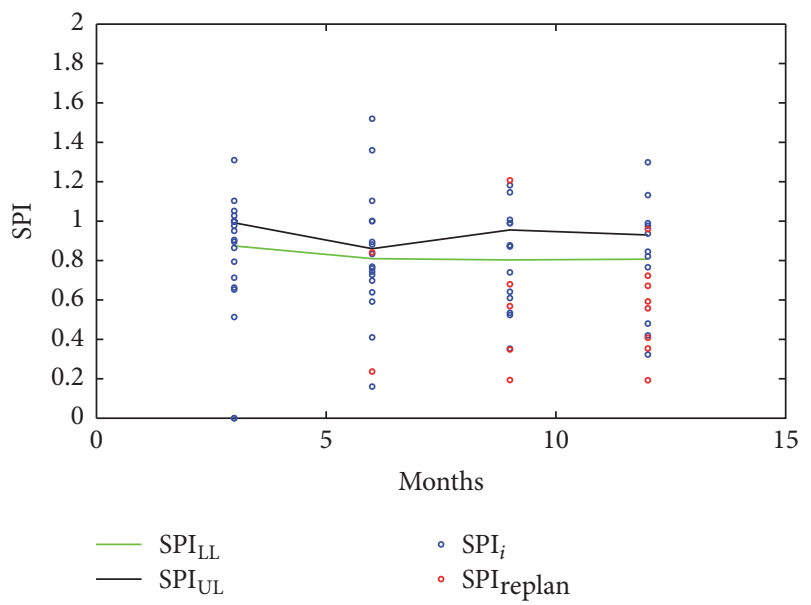

Figure 4: Comparison between $\mathrm{SPI}_{i}, \mathrm{SPI}_{\mathrm{LL}}$, and $\mathrm{SPI}_{\mathrm{UL}}$ with replanned values.

TABLE 6: Risk classification by SPI limits.

\begin{tabular}{lcccc}
\hline Risk level & \multicolumn{3}{c}{ Month } \\
& 3 & 6 & 9 & 12 \\
\hline High & 8 & 10 & 10 & 9 \\
Normal & 4 & 0 & 3 & 4 \\
Low & 7 & 9 & 6 & 6 \\
\hline
\end{tabular}

Applying these criteria in the sample without the replanned values obtains a group of construction projects displaying the need for immediate intervention to decrease the risk of delay (see Figure 3). When the construction projects discarded for being replanned were reinserted without recalculating the limiting values (see Figure 4), the calculated values were shown to be useful in decision making because only one of the reinserted values exceeded $\mathrm{SPI}_{i, \mathrm{UL}}$ at month 6 .

Applying the values given in Table 5 in the sample (Table 2) obtains the rating indicated in Table 6, in which at least eight projects are shown to display a high risk of delay, justifying interventions in the productive system to reverse the delay trend.

\section{Conclusions}

Delays are a common risk and have a significant effect on the management of construction projects. Delays damage the image of a company and contribute to higher costs. Based on data from 19 construction projects, the SPI of projects with a tendency to display delays is significantly different from SPI projects that do not show this trend.

In this sample, the probability of a project to be delayed is approximately 4 times higher than the probability of a project to not be delayed, diverting from the traditional assumption of equal probabilities. This finding reinforces the importance of the risk management of delays to minimize their occurrence and damage.

The calculation and use of SPI limits in the risk management of delays is a viable alternative to assess whether the project is exposed to a high, normal, or low risk level. An advantage of the proposed procedure is that it is a simple and quick analysis, allowing an update of the risk level in each of the project states.

This method is also advantageous in allowing any company the ability to establish limits based on their own projects. This internal data will provide a more uniform sample because variables such as organizational culture and procedures will remain constant.

\section{Competing Interests}

The authors declare that there is no conflict of interests regarding the publication of this paper.

\section{References}

[1] J. Bourn, Modernising Construction, National Audit Office, London, UK, 2001.

[2] J. Bourn, PFI: Construction Performance [Internet], HC. UK: National Audit Office, 2003, http://www.nao.org.uk/wpcontent/uploads/2003/02/0203371.pdf.

[3] E. Pereira, C. D. N. Mutti, and A. Jungles, "Prevision of delay in Brazilian residential unit construction contracts," Journal of Civil Engineering and Architecture, vol. 8, no. 1, pp. 100-106, 2014.

[4] H. Abdul-Rahman, C. Wang, and N. H. Ariffin, "Identification of risks pertaining to abandoned housing projects in Malaysia," Journal of Construction Engineering, vol. 2015, Article ID 524717, 12 pages, 2015 .

[5] K. Yeo, "Risks, classification of estimates, and contingency management," Journal of Management in Engineering, vol. 6, no. 4, pp. 458-470, 1990.

[6] K. Offei-Nyako, L. C. O. Tham, M. Bediako, C. D. Adobor, and R. O. Asamoah, "Deviations between contract sums and final accounts: the case of capital projects in Ghana," Journal of Construction Engineering, vol. 2016, Article ID 2814126, 8 pages, 2016.

[7] P. P. Shrestha, L. A. Burns, and D. R. Shields, "Magnitude of construction cost and schedule overruns in public work 
projects," Journal of Construction Engineering, vol. 2013, Article ID 935978, 9 pages, 2013.

[8] PMBoK, A Guide to the Project Management Body of Knowledge, Project Management Institute, Pennsylvania, Pa, USA, 2013.

[9] R. Chapman, "The controlling influences on effective risk identification and assessment for construction design management," International Journal of Project Management, vol. 19, no. 3, pp. 147-160, 2001.

[10] G. A. Barraza and R. A. Bueno, "Probabilistic control of project performance using control limit curves," Journal of Construction Engineering and Management, vol. 133, no. 12, pp. 957-965, 2007.

[11] G. A. Barraza, W. E. Back, and F. Mata, "Probabilistic monitoring of project performance using SS-curves," Journal of Construction Engineering and Management, vol. 126, no. 2, pp. 142-148, 2000.

[12] S. Hwang, "Dynamic regression models for prediction of construction costs," Journal of Construction Engineering and Management, vol. 135, no. 5, pp. 360-367, 2009.

[13] S. M. Trost and G. D. Oberlender, "Predicting accuracy of early cost estimates using factor analysis and multivariate regression," Journal of Construction Engineering and Management, vol. 129, no. 2, pp. 198-204, 2003.

[14] P. Gardoni, K. F. Reinschmidt, and R. Kumar, "A probabilistic framework for bayesian adaptive forecasting of project progress," Computer-Aided Civil and Infrastructure Engineering, vol. 22, no. 3, pp. 182-196, 2007.

[15] B.-C. Kim and K. F. Reinschmidt, "Probabilistic forecasting of project duration using Kalman filter and the earned value method," Journal of Construction Engineering and Management, vol. 136, no. 8, pp. 834-843, 2010.

[16] H.-H. Choi and S. Mahadevan, "Construction project risk assessment using existing database and project-specific information," Journal of Construction Engineering and Management, vol. 134, no. 11, pp. 894-903, 2008.

[17] H. Abdul-Rahman, C. Wang, and F. S. Mohamad, "Implementation of risk management in malaysian construction industry: case studies," Journal of Construction Engineering, vol. 2015, Article ID 192742, 6 pages, 2015.

[18] A. Sohrabinejad and M. Rahimi, "Risk determination, prioritization, and classifying in construction project case study: gharb tehran commercial-administrative complex," Journal of Construction Engineering, vol. 2015, Article ID 203468, 10 pages, 2015.

[19] M. R. Hallowell, K. R. Molenaar, and B. R. Fortunato III, "Enterprise risk management strategies for state departments of transportation," Journal of Management in Engineering, vol. 29, no. 2, pp. 114-121, 2013.

[20] E. M. Goldratt, Corrente Crítica, Nobel, São Paulo, Brazil, 1998.

[21] PMI PMI-, Um Guia do Conjunto de Conhecimentos em Gerenciamento de Projetos, 3a, EUA: PMI, 2013.

[22] M. M. S. Bernardes and C. T. Formoso, "Contributions to the evaluation of production planning and pontrol systems in building companies," in Proceedings of the Annual Conference of the International Group for Lean Construction, pp. 1-11, Gramado, Brazil, August 2002.

[23] K. Fung, Os Números Governam sua vida: A Influência Velada das Probabilidades e da Estatística em Tudo o que Você Faz, DVS Editora, São Paulo, Brazil, 2011.

[24] B.-C. Kim, Forecasting Project Progress and Early Warning of Project Overruns with Probabilistic Methods, Texas A\&M University, 2007. 


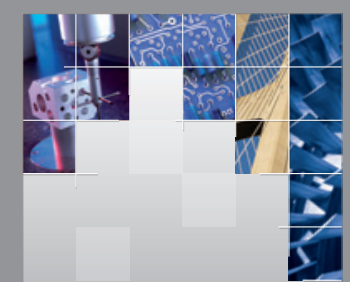

\section{Enfincering}
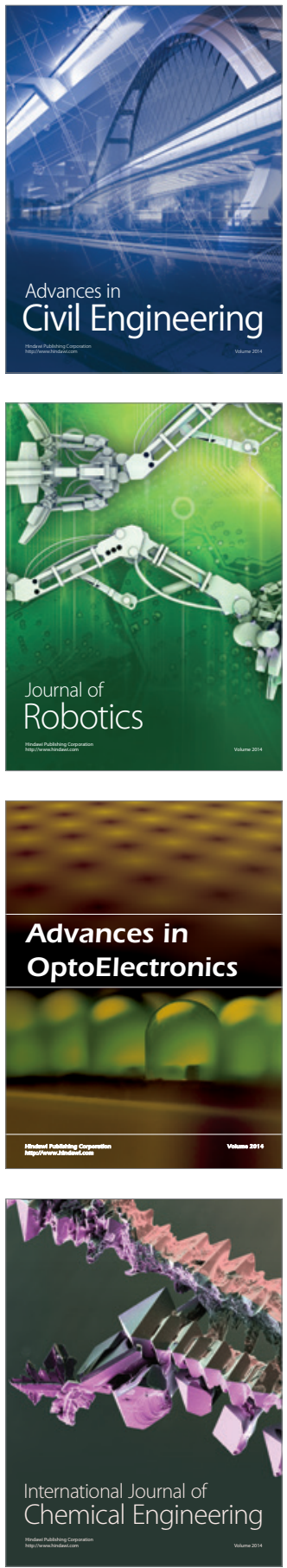

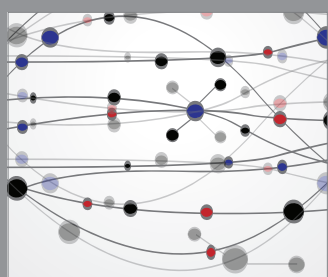

The Scientific World Journal

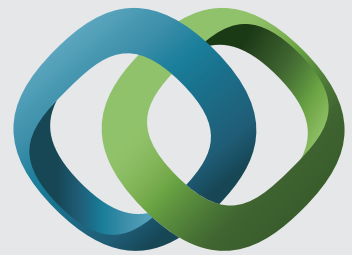

\section{Hindawi}

Submit your manuscripts at

http://www.hindawi.com
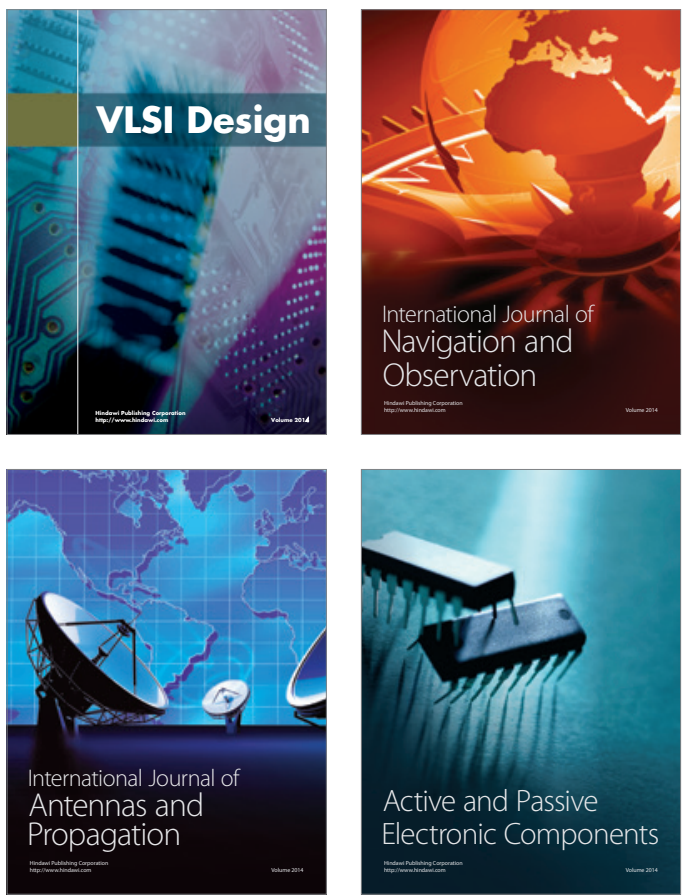
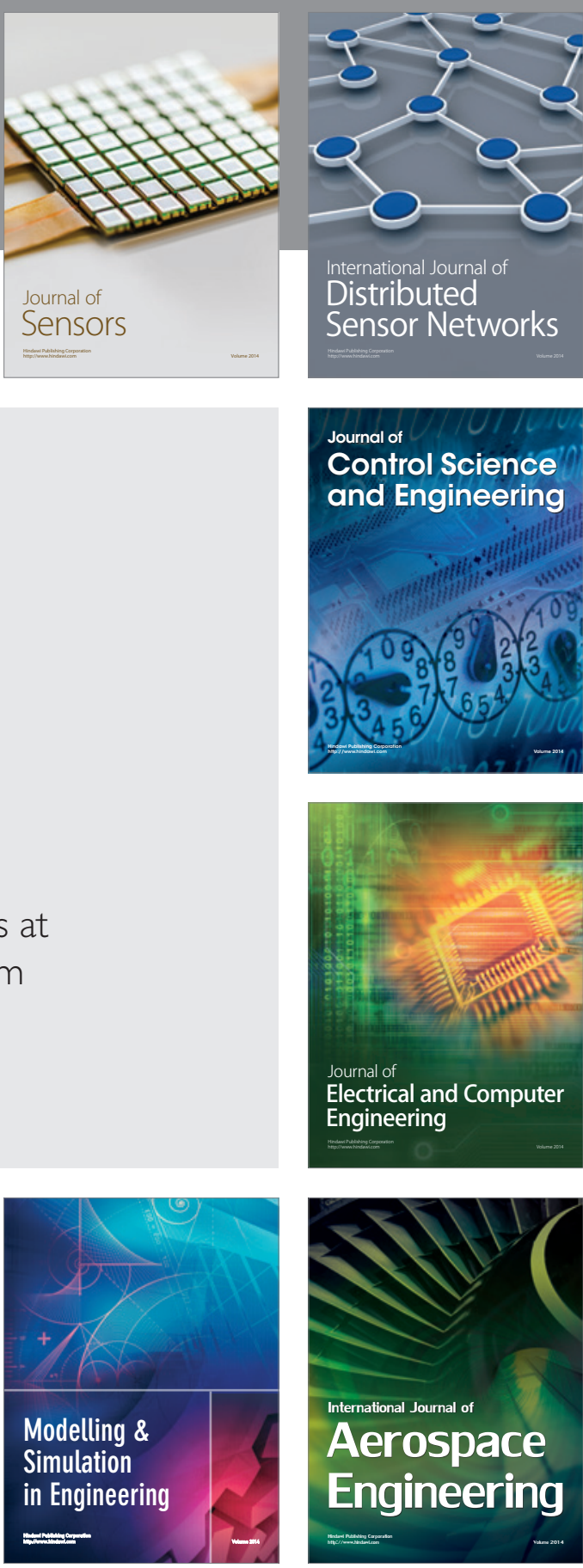

International Journal of

Distributed

Sensor Networks

Journal of

Control Science

and Engineering
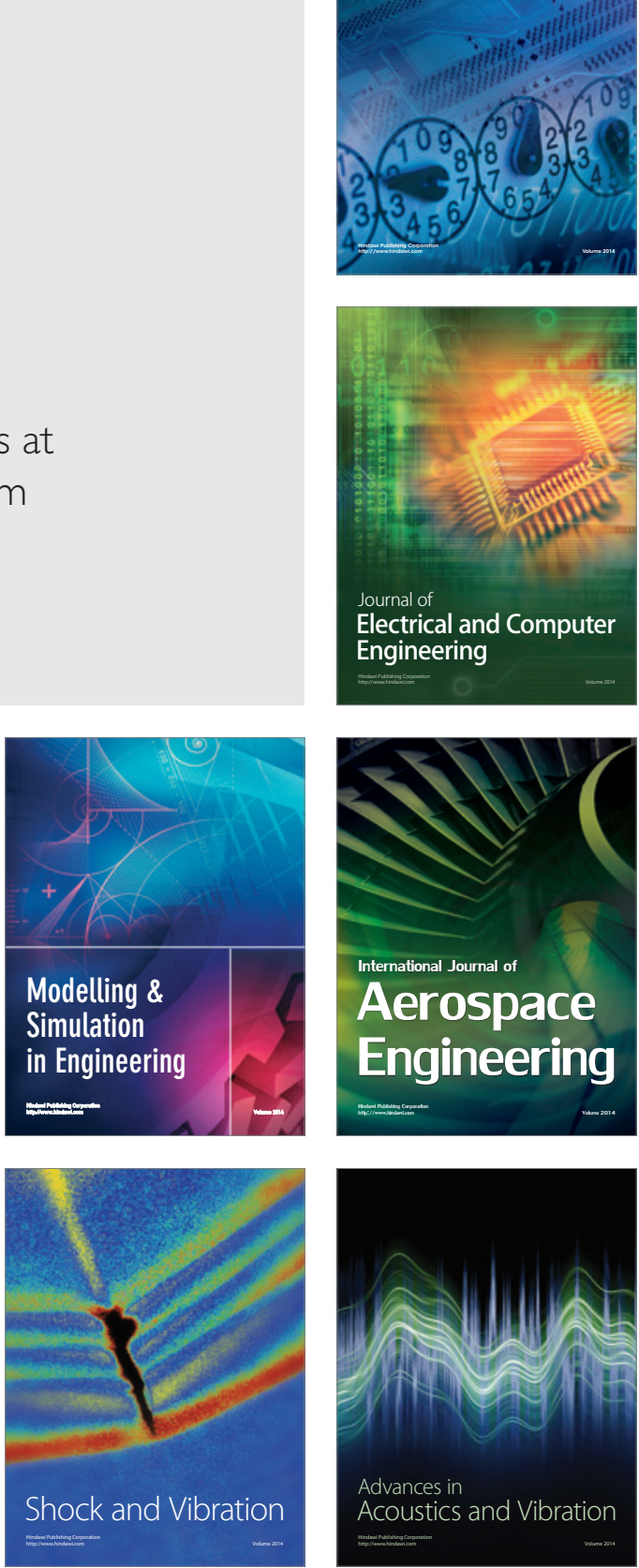